\title{
Data flow of spectral UV measurements at Sodankylä and Jokioinen
}

\author{
Jakke Sakari Mäkelä ${ }^{1, a}$, Kaisa Lakkala ${ }^{1,2}$, Tapani Koskela ${ }^{1, b}$, Tomi Karppinen ${ }^{2}$, Juha Matti Karhu ${ }^{2}$, \\ Vladimir Savastiouk $^{4}$, Hanne Suokanerva ${ }^{2}$, Jussi Kaurola ${ }^{1}$, Antti Arola ${ }^{3}$, Anders Vilhelm Lindfors ${ }^{1}$, \\ Outi Meinander ${ }^{1}$, Gerrit de Leeuw ${ }^{1,5}$, and Anu Heikkilä ${ }^{1}$ \\ ${ }^{1}$ Finnish Meteorological Institute, Research and Development, Helsinki, Finland \\ ${ }^{2}$ Finnish Meteorological Institute, Sodankylä, Finland \\ ${ }^{3}$ Finnish Meteorological Institute, Kuopio, Finland \\ ${ }^{4}$ IOS Inc, Toronto, Canada \\ ${ }^{5}$ Department of Physics, University of Helsinki, Helsinki, Finland \\ a now at: University of Jyväskylä, Jyväskylä, Finland \\ ${ }^{b}$ now: an independent researcher \\ Correspondence to: K. Lakkala (kaisa.lakkala@fmi.fi)
}

Received: 7 December 2015 - Published in Geosci. Instrum. Method. Data Syst. Discuss.: 18 January 2016 Revised: 27 April 2016 - Accepted: 2 May 2016 - Published: 9 June 2016

\begin{abstract}
The data flow involved in a long-term continuous solar spectral UV irradiance monitoring program is investigated and structured to provide an overall view on the multiphase process from data acquisition to the final products. The program employing Brewer spectrophotometers as measuring instruments is maintained by the Finnish Meteorological Institute (FMI) ever since the 1990s at two sites in Finland: Sodankylä $\left(67^{\circ} \mathrm{N}\right)$ and Jokioinen $\left(61^{\circ} \mathrm{N}\right)$. It is built upon rigorous operation routines, processing procedures, and tools for quality control (QC) and quality analysis (QA) under continuous development and evaluation. Three distinct levels of data emerge, each after certain phase in the data flow: Level 0 denoting raw data, Level 1 meaning calibrated data processed in near-real time, and Level 2 comprising of postprocessed data corrected for all distinguishable errors and known inaccuracies. The final products disseminated to the users are demonstrated to result from a process with a multitude of separate steps, each required in the production of high-quality data on solar UV radiation at the Earth's surface.
\end{abstract}

\section{Introduction}

The Brewer spectrophotometer (Brewer) was initially designed to measure total column ozone with the differential absorption method (Bais et al., 1996; Brewer, 1973) using the direct sun port. In addition, a global (diffuser) port was introduced for measurements of spectral UV. The direct sun data have also been used to calculate $\mathrm{SO}_{2}$ (Cappellani and Bielli, 1995), aerosol optical depth (Gröbner et al., 2001; Kazadzis et al., 2005; Marenco et al., 2002), and $\mathrm{NO}_{2}$ (e.g. Cede et al., 2006; Diémoz et al., 2014). At present, there are over 220 instruments set up by research institutes all over the world (http://kippzonen-brewer.com/). These instruments form an important network for monitoring changes in the atmospheric total ozone column and solar UV irradiance at the Earth's surface.

The first Brewer spectrophotometers in Finland were set up in 1990 and 1995, in Sodankylä and Jokioinen, respectively, to respond to the need to monitor total ozone and UV radiation after the discovery of the Arctic ozone loss. These time series of solar spectral UV irradiance of over 20 years are unique and among the longest measured in the Arctic. The homogenized time series have been used for several studies related to Arctic ozone loss (e.g. Eleftheratos et al., 2014; Bernhard et al., 2013; Manney et al., 2011; Knudsen et al., 1998), and validation of satellite data (Hassinen et al., 2008). They have also been used in, e.g. studies on the effects of UV radiation on biological objects (e.g. Lappalainen et al., 2010; Martz et al., 2009), materials (Heikkilä 2014), and human health (Kazantzidis et al., 2009).

The Brewer spectrophotometer is a versatile but also a complex instrument in comparison to, for instance, broad- 
band UV meters. Many intermediate steps and corrections are needed in the processing of the data. The high dynamical range of 5-6 orders of magnitude of UV irradiance reaching the surface of the Earth puts great demands on the instruments designed to monitor both the short UVB wavelengths (290-315 nm) and the longer UVA wavelengths $(315-400 \mathrm{~nm})$. The challenge is to maintain the sensitivity of the instrument at all wavelengths. The location of Finland at high latitude, where high solar zenith angles (SZAs) are frequent, brings additional challenges, as the weak signal at UVB wavelengths is near the noise level of the instrument. High-quality data can only be ensured after careful characterization of the instrument, correction of known measurement errors, and careful quality control (QC) and quality assurance (QA) (Seckmeyer et al., 2001; Garane et al., 2006; Lakkala et al., 2008; Webb et al., 2003).

Maintaining a Brewer spectrophotometer that is absolutely calibrated is a demanding task (Bernhard and Seckmeyer, 1999; Webb et al., 1998). International campaigns are regularly organized to evaluate the calibration and measurement procedures performed by different Brewers and institutes. The difficulty of the absolute calibration was already seen in the intercomparison campaigns of the 1990s (Josefsson et al., 1994; Koskela et al., 1997) and in the twenty-first century (e.g. Bais et al., 2001), in which the range of the deviations from the reference for UV spectra was up to $\pm 20 \%$. Despite the efforts to homogenize the measurements, in the last European Brewer comparison organized by the COST 1207 project in El Arenosillo, Spain, 6 Brewers out of 18 differed by more than $10 \%$ from the reference, when using the calibration provided by the operator (http://www.pmodwrc.ch/ wcc_uv/wcc_uv.php?topic=qasume_audit). The differences are most likely due to slightly different corrections (e.g temperature dependence and angular response) and processing procedures. Small variations in a number of corrections and procedures may result in large differences in the outcome.

For the comparability of the Brewer data from around the world, it is necessary to carefully document the traceability of the calibration and the processing chain of the data. Rigorous documentation should be a part of the routine QC / QA procedures at each site. This allows anyone to audit all the steps taken prior to the delivery of the data, and allows making changes in postprocessing with no need to start everything from the beginning.

This study examines and demonstrates the steps that are involved in processing different levels of solar spectral UV irradiance data produced by the Brewer spectrophotometers possessed by the Finnish Meteorological Institute. Due to economical reasons, the Brewer measurements at Jokioinen were terminated in November 2015. Since then, the Brewer no. 107 has been relocated and operated in Helsinki. Thus, this study also serves as a historical description of the Jokioinen measurements, and as a platform for the development of the procedures to be followed in Helsinki and Sodankylä in the future. A detailed description is given on the process flow from the Level 0 data (raw counts) to the Level 2 data (quality-assured spectral UV irradiances and UV products). In a companion paper (Mäkelä et al., 2016) we describe in detail how the final time series of the responsivity of a Brewer spectrophotometer is derived. In another companion paper (Heikkilä et al., 2016) we describe how the quality indicators provided by the European UV database (EUVDB) may be used for quality assurance of Level 2 data.

\section{Description of the stations}

The Finnish Meteorological Institute (FMI) has been operating Brewer spectrophotometers at two sites: Sodankylä and Jokioinen. In the following sections, brief descriptions of the characteristics of the sites and their Brewer spectrophotometers are given.

\subsection{The Sodankylä station (Brewer no. 037 and no. 214)}

The Arctic Research Centre of the FMI is located at $67.37^{\circ} \mathrm{N}, 27.63^{\circ} \mathrm{E}$, at an altitude of $179 \mathrm{~m}$ above sea level, in Sodankylä. It has maintained Brewer Mark II single monochromator spectrophotometer since 1990 . The nearby surroundings are comprised of pine forests. The river Kitinen flows in the southwest. The area is surrounded by a large peatland area in the east. The terrain is snow covered typically from October to late April. The sun is just below the horizon from mid-December to mid-January. Temperatures range from $-40^{\circ} \mathrm{C}$ in winter to $+30^{\circ} \mathrm{C}$ in summer. The station is described in more detail in, e.g. Lakkala et al. (2003).

Two Brewers are currently operated at this site: no. 037 and no. 214. They are located on the roof of the sounding station (see Fig. 1). Brewer no. 037 has a single monochromator and a wavelength range $290-325 \mathrm{~nm}$. The FWHM of the slit function is $0.56 \mathrm{~nm}$. The other Brewer, no. 214, has been set up in 2012 to work in tandem with Brewer no. 037 and to cover the longer wavelengths of the UV radiation. The wavelength range of Brewer no. 214 is $286.5-365 \mathrm{~nm}$. The FWHM of the slit function of Brewer no. 214 is $0.55 \mathrm{~nm}$.

\subsection{The Jokioinen station (Brewer no. 107)}

The meteorological observatory in Jokioinen is located at $60.82^{\circ} \mathrm{N}, 23.50^{\circ} \mathrm{E}$, at an altitude of $107 \mathrm{~m}$ above sea level, in a rural area surrounded by fields and mainly coniferous forests. The ground is covered by snow most of the time during December-March. Temperatures can range from -20 to $+30^{\circ} \mathrm{C}$.

FMI acquired and set up Brewer no. 107 in Jokioinen in 1995. Since November 2015, it has been relocated to Helsinki. At Jokioinen, Brewer no. 107 was located on the roof of the sounding station (see Fig. 2). Brewer no. 107 is type Mark III with a double monochromator. The original wavelength range of the instrument was $286.5-363 \mathrm{~nm}$. In April 1997, changes in the optics were made. Since then, the 


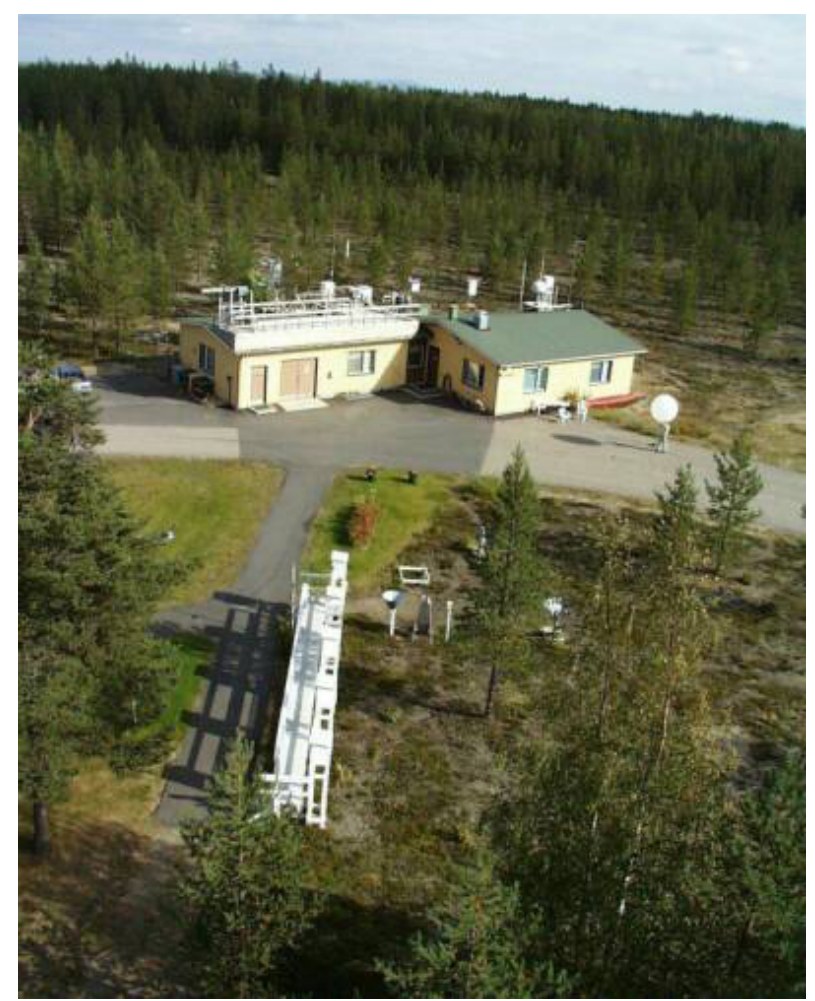

Figure 1. View of Sodankylä observatory. The Brewer is located on the roof in the enclosure on the left.

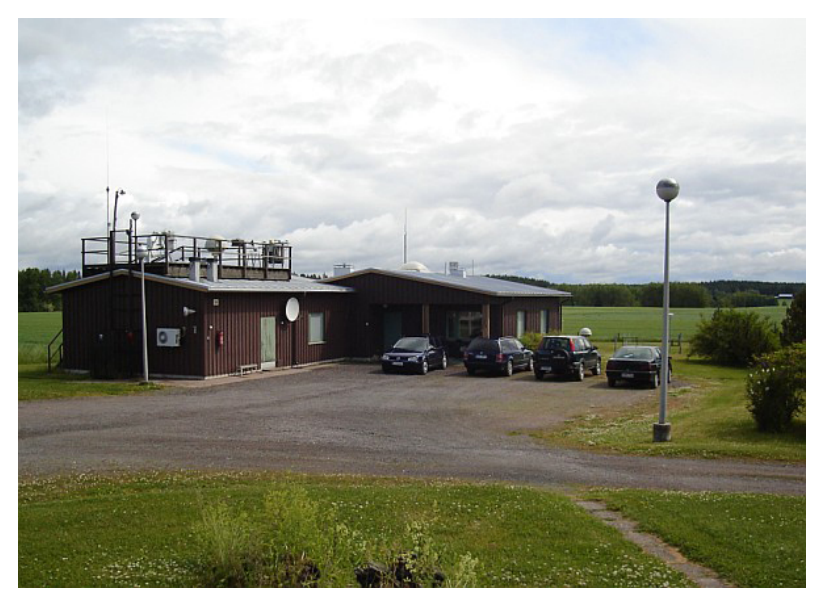

Figure 2. View of Jokioinen observatory. The Brewer is located on the roof in the enclosure on the left.

wavelength range has been $286.5-365 \mathrm{~nm}$. The FWHM of the slit function is $0.59 \mathrm{~nm}$.

\section{Data flow}

A schematic presentation on the data flow from the raw measurements performed by the FMI Brewer spectrophotometers to the final UV products is given in Fig. 3. Three levels of

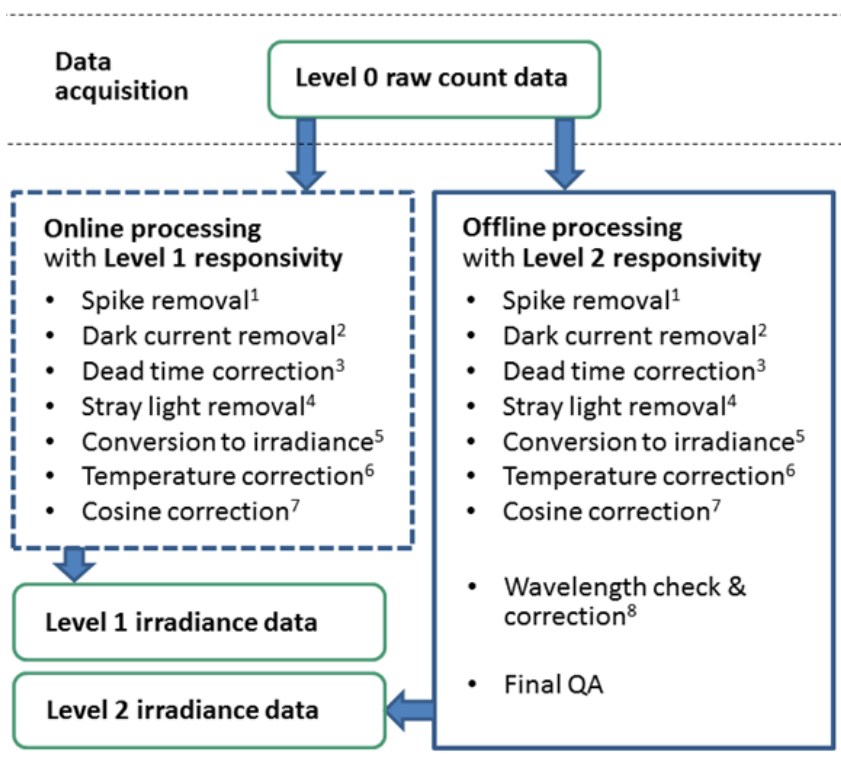

Figure 3. Schematic presentation on the data flow of Brewer UV irradiance data from the Level 0 raw counts to Level 1 and Level 2 irradiance data. ${ }^{1}$ Meinander at al. (2003); ${ }^{2}$ Eq. (1); ${ }^{3}$ Eq. (2); ${ }^{4}$ Eq. (3); ${ }^{5}$ Eq. (4); ${ }^{6}$ Eq. (5); ${ }^{7}$ Lakkala et al. (2008); ${ }^{8}$ Slaper et al. (1995).

Table 1. Information on the case UV scan of Jokioinen Brewer no. 107 selected for graphical demonstration on the phases in the data flow.

\begin{tabular}{ll}
\hline Date & 20 May 2007 \\
\hline Time of scan & $13: 20: 07-13: 25: 18$ UTC \\
SZA during the scan & $51.3-51.4^{\circ}$ \\
Total ozone column & $325 \mathrm{DU}$ \\
Visibility & $30 \mathrm{~km}$ \\
\hline
\end{tabular}

data are produced in the process. Level 0 data results from data acquisition, Level 1 data from the near-real time (NRT) processing of Level 0 data and the following QC, and Level 2 data from postprocessing of Level 0 data and the following QA.

To demonstrate the different phases in the data flow and the way the data are transformed as they go through the whole chain from the raw counts to final products, we use one selected case spectrum measured by Brewer no. 107 in Jokioinen on 20 May 2007. Information related to the case scan is given in Table 1 .

\subsection{UV data acquisition - Level 0 data}

The measurements performed by Brewer spectrophotometers are controlled through their own operating computers. In UV irradiance measurements, the quartz dome viewport is used to collect the photons from the hemisphere above. The wavelength range from the shortest wavelength to the upper limit of the range is scanned in ascending direction with $0.5 \mathrm{~nm}$ in- 


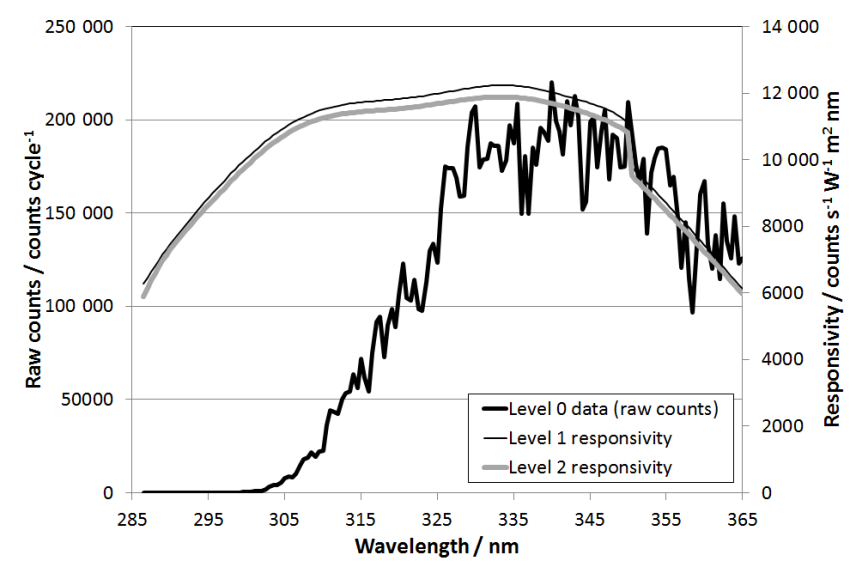

Figure 4. Example of Level 0 raw count data recorded by the Brewer no. 107 on 20 May 2007 at 13:20:07-13:25:18 UTC (on primary vertical axis) and Level 1/Level 2 responsivities of the instrument for the same day (on secondary vertical axis).

crements. The monochromator is used to select the photons on one narrow wavelength band at a time and passes them on to the photomultiplier tube (PMT) acting as a detector. The PMT makes observations in cycles: four cycles at each wavelength below $300 \mathrm{~nm}$ and two cycles at wavelengths above $300 \mathrm{~nm}$. The raw counts are stored into files onto the operating computer in units counts/cycle. These data are the Level 0 data produced by the Brewer spectrophotometer. An example of the Level 0 data raw counts is shown in Fig. 4.

The operating computers of the Brewers work autonomously, making measurements based on schedules predefined by the operator. Over the years, a variety of schedules has been used, and the schedules for the two sites have supported slightly different research targets at different times. For example, at Jokioinen, more frequent measurements have been made near sunrise and sunset, and at constant air masses, as well as at the time of the smallest SZA. At Sodankylä, measurements have generally been spread out more evenly throughout the day. At both sites, there has been a measurement at least every half hour during daylight and a measurement at midday. The number of daily UV scans at Jokioinen, for example, range from about 8 in winter to more than 30 in summer.

Other data acquired at the measurement sites and relevant to the UV data processing include visibility and total ozone column. Automatic weather stations (AWSs) produce data on visibility every $10 \mathrm{~min}$. Total ozone column measurements are performed by the Brewer spectrophotometers themselves. The data acquired on visibility and total ozone column are used in the cosine correction procedure applied to the measured UV irradiance spectra (Lakkala et al., 2008). As auxiliary measurements, a broadband UVB radiometer (Solar Light SL501A) and a pyranometer (Kipp \& Zonen CM11) measuring global radiation $(305-2800 \mathrm{~nm})$, are synchronized to the Brewer measurements. These measurements are used in offline QA procedures to identify erroneous measurements, and to obtain information on changes in the cloud cover (Lakkala et al., 2008).

The Level 0 data on solar spectral UV irradiance are transferred from the Brewer's operating computer to a central UNIX server. The raw data are further transferred to another server for the QC monitoring the proper functioning of the instrument. The system taking care of the OC is called IDEAS (Integrated Data Evaluation \& Analysis System) and is briefly described in the following section. In addition, the raw data are uploaded every $20 \mathrm{~min}$ to the $\mathrm{Eu}-$ ropean Brewer Network Database (Eubrewnet, http://rbcce. aemet.es/eubrewnet). The Eubrewnet is established within the COST 1207 project of the European Union, as a joint effort of the international Brewer community.

\subsection{IDEAS - a quality control tool}

In 2015, new software was introduced to facilitate both immediate and long-term quality control of data, and to improve the potential of the Brewers to work as real-time operational devices. IDEAS (supplied by Full Spectrum Science Inc.) is a tool using the Level 0 data directly for checking that the Brewer is functioning correctly. The Brewer itself makes several check measurements during the day. The measured parameters are used to monitor the stability of the instrument.

Every measurement of the Brewer and every process of the operating software is recorded in appropriate data files. These are stored as so-called B-files, and updated to the server in which IDEAS is running. IDEAS is integrated with the real-time 24/7 operational control system of FMI. Automatic warnings of malfunctions of the Brewer are generated within 5-10 min and sent to the $24 / 7$ control center. If the personnel there are unable to solve the problems, standby Brewer specialists can be alerted by text messages when needed.

The IDEAS software analyses all records collected by the Brewer spectrophotometer operational program (see Savastiouk (2011) for a description of an earlier version of the software). These records include observations, tests, and user comments. For each record type that is known to the system, the results are compared to nominal or reference values, prioritized and reported to the main FMI observation database system with flags indicating the state of the instrument. For record types that are not yet known to the system, a report is created so new record types can be added to the system analysis. All data are stored in a database for easy access at any time.

The full list of currently analysed records contains over a hundred items. Some of the most relevant critical tests include the wavelength calibration internal mercury lamp test (HG); the linearity, or dead time, test (DT); and the spectral sensitivity stability test on the internal halogen lamp (SL). Failures in any of these tests suggest that other data collected at the same time are questionable and need attention from the 
operator and/or a scientist. In such cases, an immediate alert is sent to the people responsible for the instrument to address these failures.

Both a real-time and historical reporting tool is also part of IDEAS. The tool generates a collection of prioritized tables and plots that include test results as well as ozone data comparison with satellites as an informational aid for the user to evaluate the data quality.

\subsection{UV data processing}

For the processing of solar spectral UV irradiance data produced by the Brewer spectrophotometers, two separate lines have been established. The first is used for online NRT processing, using the Level 0 data and auxiliary data as input to produce Level 1 data. The second is employed in offline postprocessing, using the same data as input but employing a re-evaluated time series of responsivity of the instrument, correction for potential shifts in the wavelength scale, and final QA procedures. In both processing schemes, knowledge on the responsivity of the instrument is needed for the production of calibrated irradiance data.

\subsubsection{Calibration with Level 1 and Level 2 responsivities}

In order to convert the measured photon counts into irradiances, the response of the instrument must be known. The response is determined using $1 \mathrm{~kW}$ lamp measurements performed in an optical laboratory. The optical laboratory facilities at Sodankylä are described in Lakkala et al. (2016). The optical laboratory facilities at Jokioinen are similar to those at Sodankylä.

The calibration lamps are tungsten-filament incandescent halogen lamps of type DXW operated in vertical beam direction. A primary standard is used to transfer the irradiance scale from the National Standard Laboratory MIKES-Aalto. Using the measurements of the Brewer, the scale is transferred to working standards used for the calibration of the Brewer every 6 weeks. Usually at least three lamps are measured during one calibration event, which enables the detection of potential drifts in the lamps (Webb et al., 1998; Lakkala et al., 2008). The obtained responsivity is used in the online NRT processing and production of Level 1 data until the next calibration. Garane et al. (2006) have calculated that the typical uncertainty of the UV irradiances due to the absolute calibration uncertainty is $1.4 \%$.

The determination of the Level 2 responsivity with daily values is briefly described in Lakkala et al. (2008) and is covered in more detail in the companion paper (Mäkelä et al., 2016). In brief, calibration lamp measurements are analysed back in time on a longer time span and measurements of all lamps are incorporated in crosschecking and comparison, to separate the long-term drifts of the lamps from transient exceptions in their output, and to confirm the selection
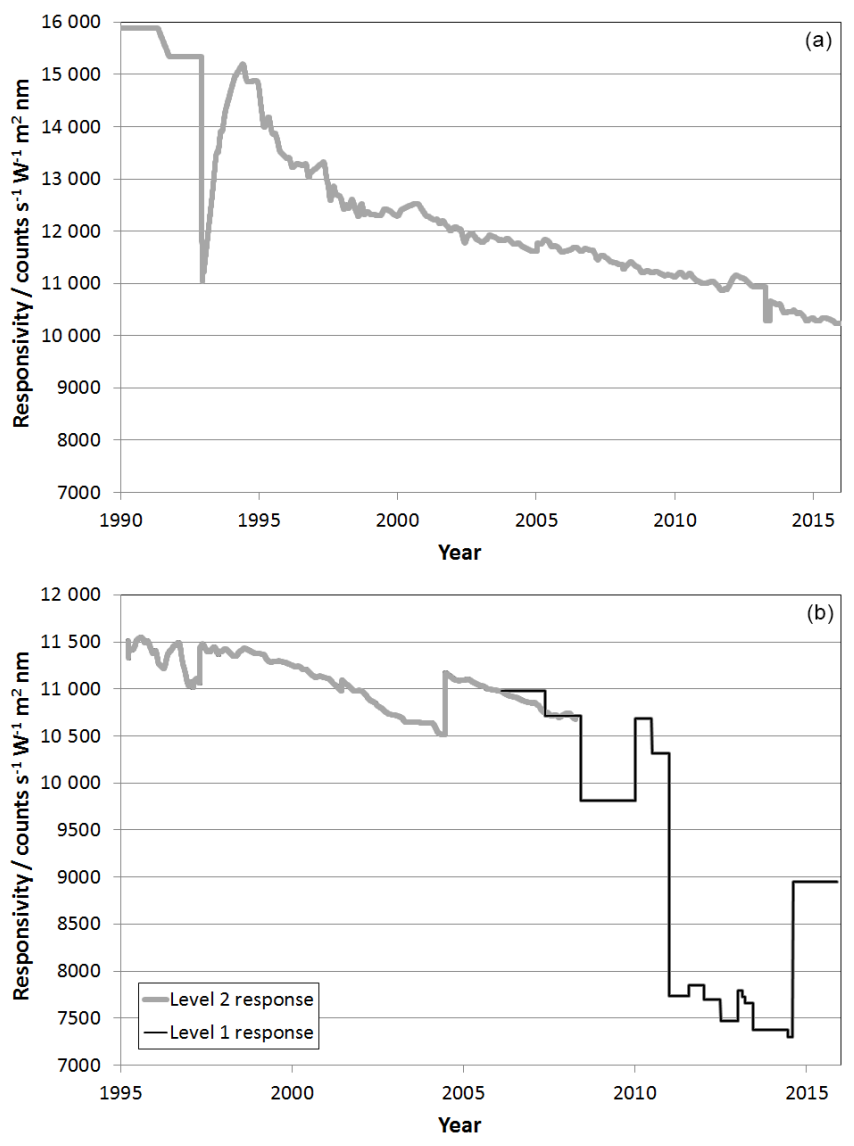

Figure 5. (a) Time series of Level 2 responsivity of Brewer no. 037 at $305 \mathrm{~nm}$. (b) Partly overlapping time series of Level 1 and Level 2 responsivities of Brewer no. 107 at $305 \mathrm{~nm}$.

of the core "trusted" lamps that serve as the basis for the final Level 2 calibration. This analysis results in a response time series with daily responsivities over the time period investigated. The time series is formed by linear interpolation between the moments of lamp measurements and smoothed by using a moving average.

Examples of the responsivities are shown in Fig. 4. The Level 1 and 2 responsivities plotted in the figure have been applied in the online NRT and offline postprocessing of the raw counts recorded by Brewer no. 107 on 20 May 2007 (the case scan described in Table 1). The interpolated and smoothed time series of Level 2 responses at $305 \mathrm{~nm}$ for Brewer no. 037 is shown in Fig. 5a to demonstrate the temporal development of the response of the instrument. In Fig. 5b, the stepwise time series of Level 1 and the interpolated and smoothed time series of Level 2 responsivities at $305 \mathrm{~nm}$ for Brewer no. 107 are also shown partly overlapping to illustrate the difference between the responsivities used in Level 1 and Level 2 processing.

Between the $1 \mathrm{~kW}$ lamp calibrations performed in the laboratory, the stability of the Brewer is monitored onsite every 3 weeks using external $50 \mathrm{~W}$ lamp measurements. In those 
measurements, at least three lamps are used as well. If a change in the spectral response of the Brewer is detected, the Brewer is moved to the laboratory for absolute calibration.

\subsubsection{Processing algorithms}

Both the online and offline data processing are done using custom-made software written in Perl (Practical Extraction and Report Language) and supported by shell scripts. The original software provided by the instrument manufacturer and the algorithms therein have served as a basis for the software development. The algorithms have been described in detail by Lakkala et al. (2008). Only the key points are therefore summarized in the following.

The Brewers perform the scans by starting from the shortest and ending at the longest wavelength of the wavelength range of the instrument. The Brewer software also returns the dark current $F 1$, for each scan. The total scanning time is about $4 \mathrm{~min}$ for Brewer no. 037 and $5 \mathrm{~min}$ for Brewers no. 107 and no. 214 due to the larger wavelength range. The occasionally occurring noise spikes are first removed based on the method of Meinander et al. (2003). Following SCITEC Instruments Inc. (1999), the raw counts $F$ (in units counts cycle ${ }^{-1}$ ) recorded by the Brewer are next converted to count rates $C$ (counts $\mathrm{s}^{-1}$ ) by subtracting the dark counts $F 1$ and taking into account the integration time IT and the number of cycles $\mathrm{CY}$ of the slit exposure. The integration time is predefined as $0.1147 \mathrm{~s}$. For each wavelength $i$, where $i=290-325(365) \mathrm{nm}$, the dark current corrected count rate is calculated as

$C_{i}=\frac{2\left(F_{i}-F 1\right)}{\mathrm{CY} \cdot \mathrm{IT}}$.

The dead time DT of the photomultiplier is measured daily and taken into account using Poisson statistics. Nine iteration rounds $(n=0-8)$ are next used to correct the count rate for the DT:

$C_{i}(n)=C_{i}(0) \cdot e^{C_{i}(n) \cdot \mathrm{DT}}$.

The stray light is calculated as the average of all counts below $292 \mathrm{~nm}$ (no. 107 and no. 214) or $293 \mathrm{~nm}$ (no. 037). The count rate corrected for stray light is simply

$C_{i}=C_{i}-\frac{1}{N} \sum_{i<292(3)} C_{i}$,

where $N$ is the number of wavelengths below the stray light limit. Since no. 107 and no. 214 have a double monochromator, the stray light counts are small. The Sodankylä Brewer no. 037 has a single monochromator, and the stray light counts are larger (Bais et al., 1996).

The count rates are then converted to irradiances by dividing the count rate $C_{i}$ with the spectral response $R_{i}$ of the instrument:

$I_{i}=\frac{C_{i}}{R_{i}}$.
Temperature and cosine corrections are then made to the spectral irradiances. A linear dependence for temperature is assumed:

$I_{i}=I_{i} \cdot\left(1+\mathrm{CT}_{i} \cdot \Delta T\right)$,

where $\mathrm{CT}_{i}$ is the temperature correction coefficient and $\Delta T$ is the temperature difference between the measurement temperature and the reference temperature.

The cosine correction is based on radiative transfer calculations (Lakkala et al., 2008). As both the direct and the diffuse component of the global radiation affect the cosine correction factor, we need to estimate the ratio of the direct and diffuse components of the actual global radiation. This is done using the freely available libRadtran package (Mayer and Kylling, 2005). The only unknown input parameter to the model is the cloud optical depth, which is estimated using a predefined lookup table. The input to the lookup table include the total ozone (measured with the Brewer), the irradiance given by the Brewer, the solar zenith angle, the visibility (given by the AWS), and the albedo. Currently, a fixed albedo value of 0.03 is used for both stations, corresponding to the average summer albedo.

\subsubsection{Online processing - Level 1 data}

The components of the online NRT processing scheme are described in Fig. 6. Processing of all the data from both stations is done at a single central Unix server. The raw (Level 0) data are transferred from the Brewer operational computer to the central server every $5 \mathrm{~min}$. From the central computer the data are further transferred to the IDEAS server, where the QC of the data is done. Every 5-10 min, status messages are sent to the observation control server, from which the critical status messages are transferred to the 24/7 control of FMI. Level 0 data are also transferred to the European Brewer database Eubrewnet, every $20 \mathrm{~min}$. As soon as a new UV measurement has been detected by the central server, the data processing of Level 1 data starts and visibility is downloaded from the climate database of FMI, and used for the cosine correction of the data. The Level 1 data are then used to calculate products which are transferred to a server with a web interface and the climate data base of FMI. The reference data from the broadband SL501A radiometer and the global radiation pyranometer CM11 are downloaded each time a spectral measurement is made. An example of the Level 1 irradiance spectrum is given in Fig. 7.

The Level 1 data are spectral UV irradiance processed in near-real time. Several corrections are routinely made in the Level 1 processing, and several data products are derived. In addition to the near-real-time measurements, every morning the data from the previous day are reprocessed. This is mainly done to avoid data gaps in Level 1 data. Such gaps might, for example, occur if there has been a malfunction of the central server, in which case the Level 1 spectra have 


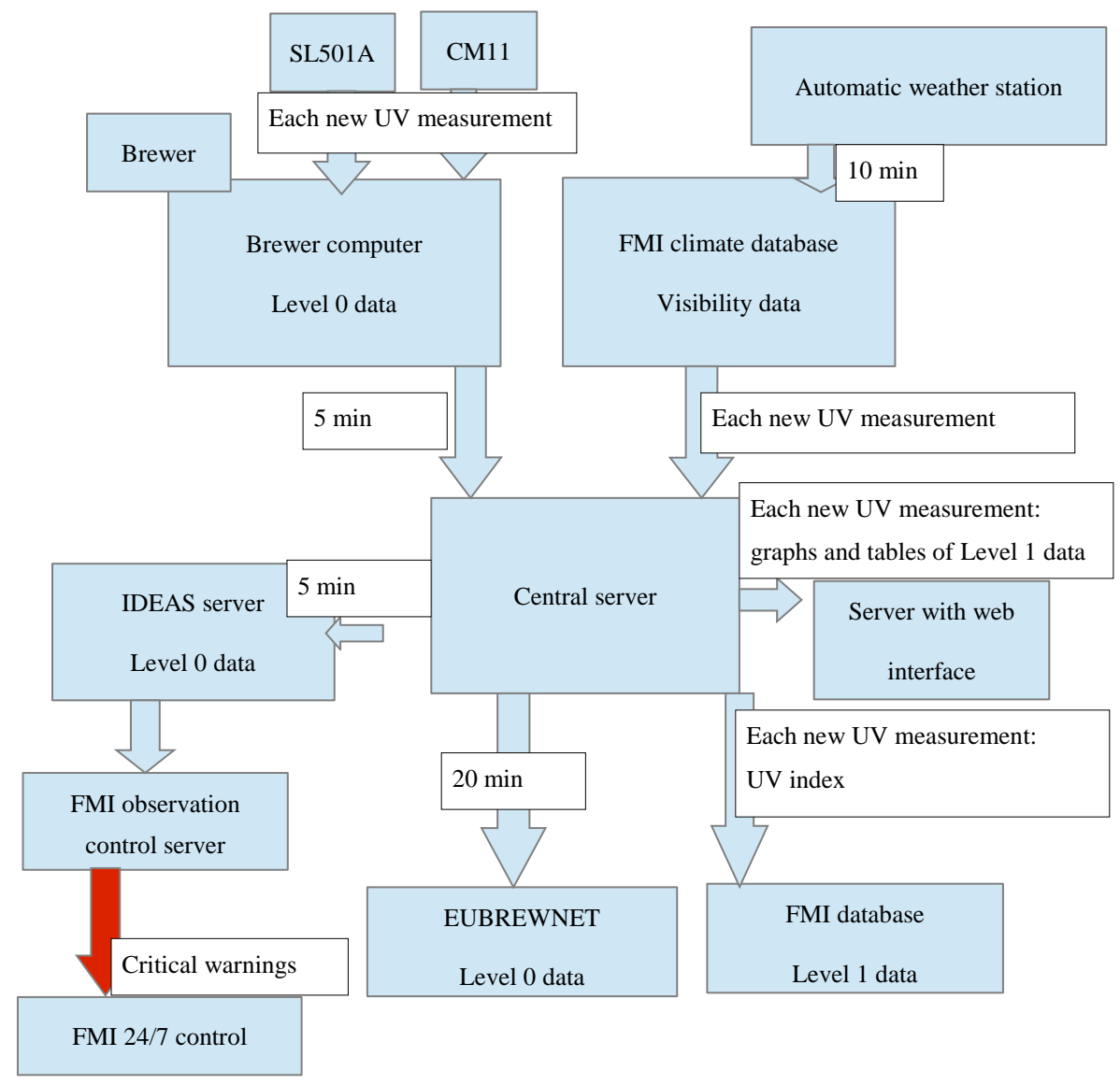

Figure 6. Schematic presentation of Brewer NRT data processing.

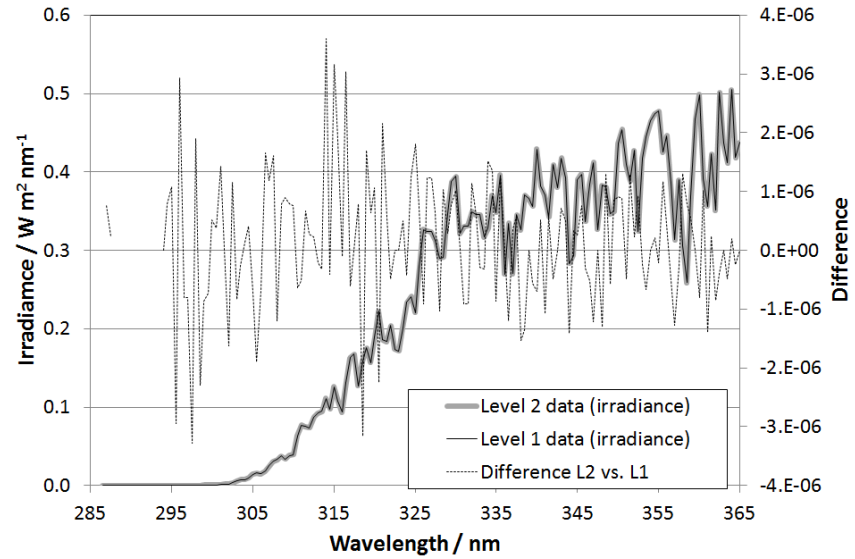

Figure 7. Examples of the Level 1 and Level 2 Brewer irradiance spectra.

not been calculated even though the Level 0 data from the Brewer are still available.

\subsubsection{Offline processing - Level 2 data}

Level 1 spectral irradiance data are produced using the Level 1 responsivity updated regularly on the basis of the calibration lamp measurements. To produce Level 2 data, calibration lamp measurements are analysed back in time to produce response time series as described in Sect. 3.3.1. By this procedure, the potential drifts in the calibration lamps, possibly affecting the Level 1 responsivity, are eliminated. This correction can be calculated once a year, when the primary calibration lamps are recalibrated. The Level 2 data are fully homogenized and quality assured. The SHICRIVM algorithm (Slaper et al., 1995) is used to correct for wavelength shifts. As a quality control tool, the dose rates are compared with reconstructed UV, model calculations of clear sky UV and global radiation, global radiation and broad band UV data in order to distinguish erroneous measurements (Lakkala et al., 2008). Erronous measurement can be distisguihed by a considerable difference between the above-mentioned modelled or measured ancillary data and the Brewer UV data. In addition each spectrum is checked visually and bad measurements are excluded. An example of the Level 2 irradiance spectrum is given in Fig. 7. 
Table 2. Action spectra used routinely in the processing to derive weighted dose rates from Brewer UV measurements.

\begin{tabular}{ll}
\hline Action spectrum & Reference \\
\hline Erythema (CIE weighting function) & McKinlay et al. (1987) \\
Skin cancer in mice corrected for human skin, 299 nm normalization & de Gruijl and van der Leun (1994) \\
UVB non-weighted 290-320 nm & - \\
UVB non-weighted 290-15 nm & - \\
UVA non-weighted 315-400 nm & - \\
Generalized plant response (normalized at 300 nm); & Caldwell et al. (1986) \\
DNA damage; & Setlow (1974) \\
Photosynthesis inhibition; & Mitchell (1990) \\
Previtamin D & CIE (2006) \\
\hline
\end{tabular}
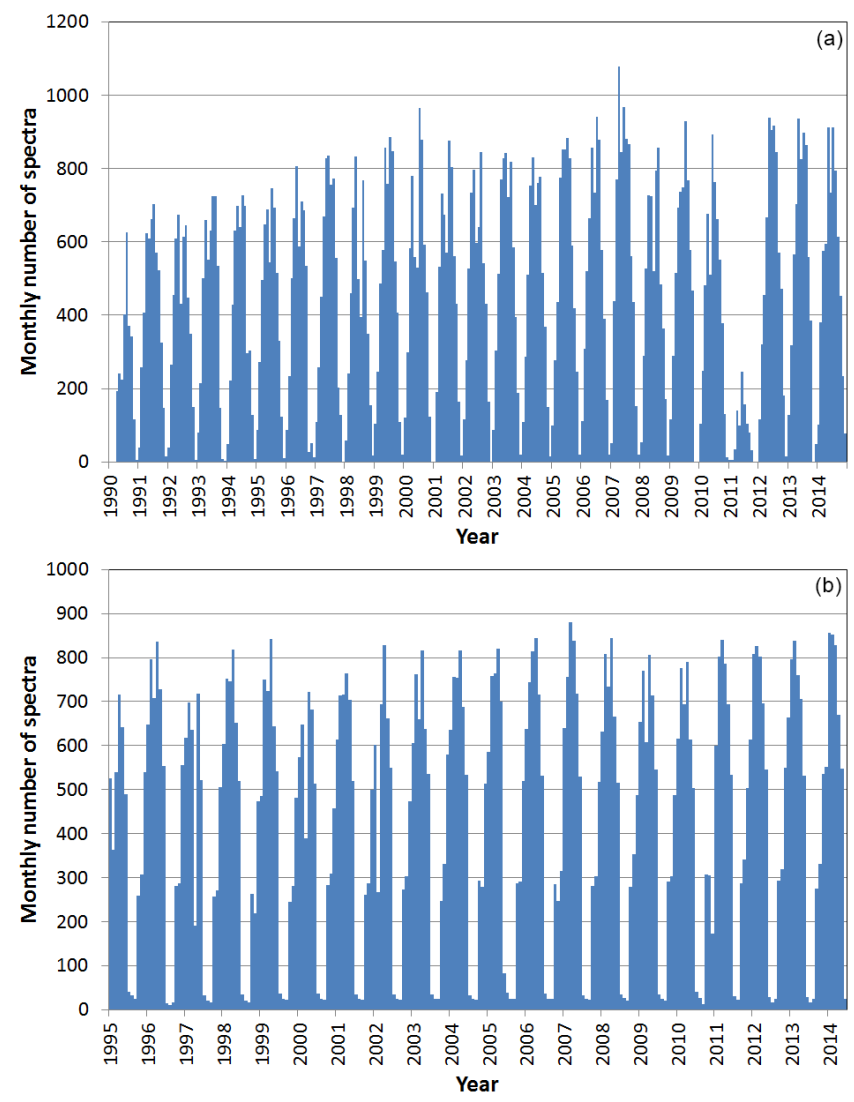

Figure 8. (a) Number of monthly UV irradiance spectra submitted to the EUVDB measured by the Brewer no. 037 during 1990-2014. (b) Number of monthly UV irradiance spectra submitted to the EUVDB measured by the Brewer no. 107 during 1995-2014.

Once a year, the Level 2 data are uploaded to the database EUVDB (http://uv.fmi.fi/uvdb/). Figure 8 shows the number of UV spectra submitted to the EUVDB measured by the Brewer no. 037 (Fig. 8a) and Brewer no. 107 (Fig. 8b) during 1990-2014 and 1995-2014, respectively. The submission of Brewer no. 037 spectra for 2011 will be upgraded in the near future, as there exists more than 5700 spectra for that year, but only some of them have been submitted to the database

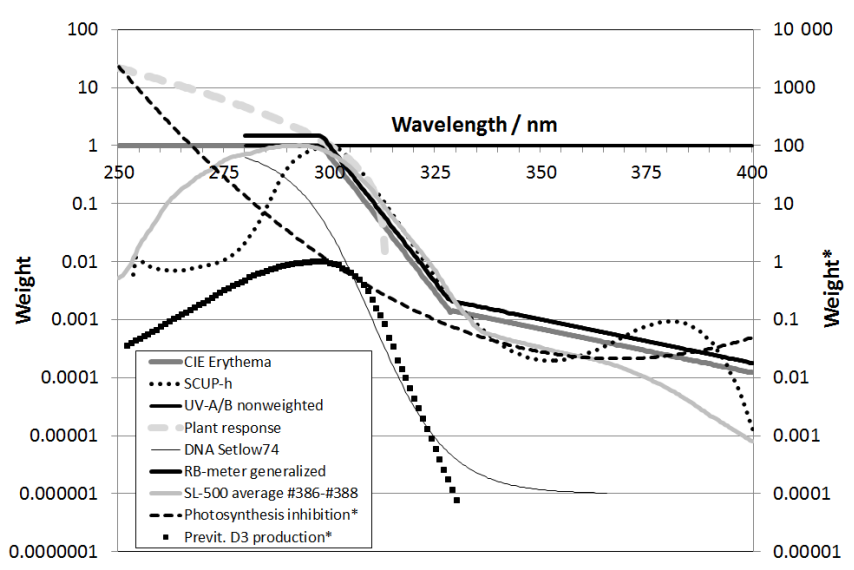

Figure 9. Action spectra used routinely in the processing to derive weighted dose rates from Brewer UV measurements.

at the time of writing the paper. The data from Sodankylä are also uploaded to the database of the FMI-Arctic Research Centre (http://litdb.fmi.fi/).

\subsubsection{Products}

Several products are derived from the Level 1 and Level 2 spectral data. These include dose rates (in $\mathrm{W} \mathrm{m}^{-2}$ ) and daily doses (in $\mathrm{J} \mathrm{m}^{-2}$ ) as unweighted and weighted by selected action spectra (Table 2 and Fig. 9). Let us denote an arbitrary action spectrum by $s(\lambda)$. The dose rate $\dot{D}$ is calculated from the irradiance spectrum $E \lambda$, multiplied by the action spectrum, by numerical integration over the appropriate wavelength range (UV, UVA, or UVB):

$\dot{D}=\int_{\lambda_{\min }}^{\lambda_{\max }} s(\lambda) \cdot E(\lambda) d \lambda$.

For the unweighted quantities, $s(\lambda)$ is equal to unity. The daily dose is further derived from the dose rate by numeri- 


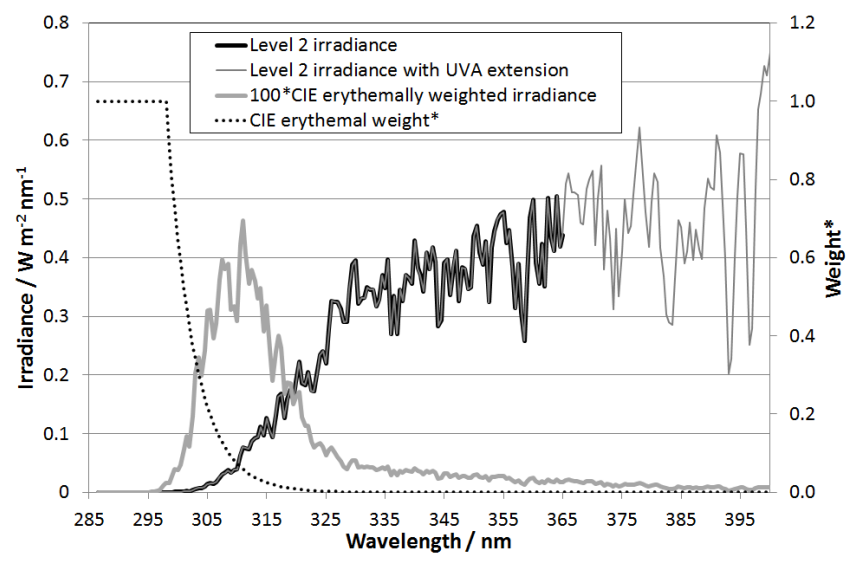

Figure 10. Example of the UVA extension to a spectrum and calculation of the corresponding dose rate weighted with the CIE erythemal action spectrum.

cal integration over the day:

$D=\int_{t_{\min }}^{t_{\max }} \dot{D} \mathrm{~d} t$.

The derivation of the products is illustrated in Fig. 10. The action spectra currently in routine use are listed in Table 2. UV index is additionally derived by multiplying the CIE erythemally weighted UV dose rate by 40 (WMO, 1997).

For the calculation of the dose rates requiring integration beyond the upper wavelength limit of the Brewer, the measured spectra are extended using a predefined reference UVA spectrum (Fig. 10). The extension is adjusted onto the level of the measured spectrum by linear conversion. The ratio of the measured irradiance to the reference irradiance at selected wavelength is used as a scaling factor. For Brewer no. 037, the wavelength of $324 \mathrm{~nm}$, and for Brewer no. 107 and no. 214, the wavelength of $361 \mathrm{~nm}$ is used as a point of adjustment. All action spectra in routine processing (Fig. 9) approach zero towards the longer UVA wavelengths. This means that the uncertainty caused by the artificial UVA extension to the computed dose rate is of the order of $10^{-3}$. For the unweighted UV and UVA dose rates, our investigation based on a radiative transfer model simulation suggests uncertainties as high as approx. $2 \%$ caused by the constant scaled UVA extension. This finding is in line with the result obtained by Fioletov et al. (2004).

All products are stored in the central server, and graphs and statistical tables are updated each time a new measurement is processed. The data are transferred to a server which has a web interface for internal use at FMI. This information is used at FMI for operational and research purposes. In addition, the Level $1 \mathrm{UV}$ index is transferred NRT to the FMI climate database.

\section{Conclusions}

Production of high-quality data on solar spectral UV at the Earth's surface requires a complex set of operation routines, processing algorithms, and QC / QA procedures. We have described and demonstrated the methods used in the acquisition and processing of solar spectral UV irradiance data measured by Brewer spectrophotometers in Finland. As a result, we have produced a comprehensive view on the multiphase data flow from the collection of single UV photons to calculation of final products of UV irradiance. This is expected to facilitate identification and isolation of specific targets of development in the procedures used in different phases of the data flow. The first targets of this kind appear to be the implementation of solar zenith angle and total column ozone dependent UVA extension to the measured spectra in the calculation of the different UV dose rates. Another emerging idea has been the development of a comprehensive data and metadata management system to support the data flow as a whole and to ensure its continuance.

Due to economical reasons, solar spectral UV measurements at the Jokioinen observatory were terminated in November 2015, and the Brewer no. 107 was transferred to and set up for measurements in Helsinki, the capital city of Finland. The 20-year time series of solar spectral UV irradiance obtained in Jokioinen is in the process of being analysed. The methods and procedures reported in this study are still in continuous use in Helsinki and Sodankylä. Brewer no. 037 is still operated in Sodankylä and continues to collect its over 25-year record of solar spectral UV measurements. In Helsinki, a new time series has been initiated with Brewer no. 107. Thorough understanding on the different phases in the data flow and further development of the methods is a prerequisite for the vitality of the monitoring programs also in the future.

Acknowledgements. Esko Kyrö is acknowledged for starting the Brewer measurements at Sodankylä. We are grateful to the operators at Sodankylä and Jokioinen stations for daily maintenance and for performing the calibrations of the Brewers. We thank the Brewer community within the COST 1207 project for sharing expertise related to Brewer measurements.

Edited by: N. Partamies

\section{References}

Bais, A., Zerefos, C., and McElroy, C.: Solar UVB measurements with the double- and single-monochromator Brewer Ozone Spectrophotometers, Geophys. Res. Lett., 23, 833-836, 1996.

Bais, A. F., Gardiner, B. G., Slaper, H., Blumthaler, M., Bernhard, G., McKenzie, R., Webb, A. R., Seckmeyer, G., Kjeldstad, B., Koskela, T., Kirsch, P. J., Gröbner, J., Kerr, J. B., Kazadzis, S., Leszczynski, K., Wardle, D., Josefsson, W., Brog- 
niez, C., Gillotay, D., Reinen, H., Weihs, P., Svenoe, T., Eriksen, P., Kuik, F., and Redondas, A.: SUSPEN intercomparison of ultraviolet spectroradiometers, J. Geophys. Res., 106, 1250912525, doi:10.1029/2000JD900561, 2001.

Bernhard, G., Dahlback, A., Fioletov, V., Heikkilä, A., Johnsen, B., Koskela, T., Lakkala, K., and Svendby, T.: High levels of ultraviolet radiation observed by ground-based instruments below the 2011 Arctic ozone hole, Atmos. Chem. Phys., 13, 10573-10590, doi:10.5194/acp-13-10573-2013, 2013.

Bernhard, G. and Seckmeyer, G.: Uncertainty of measurements of spectral solar UV irradiance, J. Geophys. Res., 104, 1432114345, 1999.

Brewer, A. W.: A replacement for the Dobson spectrophotometer?, Pure Appl. Geophys., 106-108, 919-927, 1973.

Caldwell, M. M., Camp, L. B., Warner, C. W., and Flint, S. D.: Action spectra and their key role in assessing biological consequences of solar UV-B radiation change, edited by: Worrest, R. C. and Caldwell, M. M., Stratospheric ozone reduction, solar ultraviolet radiation and plant life, Springer-Verlag, Berlin, 87$111,1986$.

Cappellani, F. and Bielli, A.: Correlation between $\mathrm{SO}_{2}$ and $\mathrm{NO}_{2}$ measured in an atmospheric column by a Brewer spectrophotometer and at ground-level by photochemical techniques, Environ. Monit. Assess., 35, 77-84, 1995.

Cede, A., Herman, J., Richter, A., Krotkov, N., and Burrows, J.: Measurements of nitrogen dioxide total column amounts using a Brewer double spectrophotometer in direct Sun mode, J. Geophys. Res. 111, D05304, doi:10.1029/2005JD006585, 2006.

CIE (International Commission on Illumination), Action spectrum for the production of previtamin D3 in human skin, CIE, 174, 2006.

de Gruijl, F. R. and van der Leun, J. C.: Estimate of the wavelength dependency of ultraviolet carcinogenesis in humans and its relevance to the risk assessment of a stratospheric ozone depletion, Health Phys., 67, 319-325, 1994.

Diémoz, H., Siani, A. M., Redondas, A., Savastiouk, V., McElroy, C. T., Navarro-Comas, M., and Hase, F.: Improved retrieval of nitrogen dioxide $\left(\mathrm{NO}_{2}\right)$ column densities by means of MKIV Brewer spectrophotometers, Atmos. Meas. Tech., 7, 4009-4022, doi:10.5194/amt-7-4009-2014, 2014.

Eleftheratos K., Kazadzis, S., Zerefos, C. S., Tourpali, K., Meleti, C., Balis, D., Zyrichidou, I., Lakkala, K., Feister, U., Koskela, T., Heikkilä, A., and Karhu, J. M.: Ozone and Spectroradiometric UV Changes in the Past 20 Years over High Latitudes, Atmos. Ocean., 53, 117-125, doi:10.1080/07055900.2014.919897, 2014.

Fioletov, V. E., Kimlin, M. G., Krotkov, N., McArthur, L. J. B., Kerr,J. B., Wardle, D. I., Herman, J. R., Meltzer, R., Mathews, T. W., and Kaurola, J.: UV index climatology over the United States and Canada from ground-based and satellite estimates, J. Geophys. Res., 109, D22308, doi:10.1029/2004JD004820, 2004.

Garane, K., Bais, A. F., Kazadzis, S., Kazantzidis, A., and Meleti, C.: Monitoring of UV spectral irradiance at Thessaloniki (19902005): data re-evaluation and quality control, Ann. Geophys., 24, 3215-3228, doi:10.5194/angeo-24-3215-2006, 2006.

Gröbner, J., Vergaz, R., Cachorro, V. E., Henriques, D. V., Lamb, K., Redondas, A., Vilaplana, J. M., and Rembges, D.: Intercomparison of aerosol optical depth measurements in the UVB us- ing Brewer spectrophotometers and a Li-Cor spectrophotometer, Geophys. Res. Let. 28, 1691-1694, 2001.

Hassinen S., Tamminen, J., Tanskanen, A., Koskela, T., Karhu, J. M., Lakkala, K., and Mälkki, A.: Description and Validation of the OMI Very Fast Delivery Products, J. Geophys. Res., 113, D16S35, doi:10.1029/2007JD008784, 2008.

Heikkilä, A.: Methods for assessing degrading effects of UV radiation on materials, Finnish Meteorological Institute Contributions, 111, Unigrafia Oy, Helsinki, 41 pp., 2014.

Heikkilä, A., Kaurola, J., Lakkala, K., Karhu, J. M., Kyrö, E., Koskela, T., Engelsen, Slaper, O. H., and Seckmeyer, G.: European 1 UV DataBase (EUVDB) as a repository and quality analyzer for solar spectral UV irradiance monitored in Sodankylä, Geosci. Instrum. Method. Data Syst. Discuss., doi:10.5194/gi2015-39, in review, 2016.

Josefsson, W., Koskela, T., Dahlback, A., and Eriksen, P.: Spectral sky measurements, in: The Nordic intercomparison of ultraviolet and total ozone instruments at Izaña from 24 October to 5 November 1993, final report, edited by: Koskela, T., Finnish Meteorological Institute, Meteorological publications No. 27, Helsinki, 73-80, 1994.

Kazadzis, S., Bais, A., Kouremeti, N., Gerasopoulos, E., Garane K., Blumthaler, M., Schallhart, B., and Cede, A.: Direct spectral measurements with a Brewer spectroradiometer: Absolute calibration and aerosol optical depth retrieval, Appl. Opt., 44, 16811690, 2005.

Kazantzidis, A., Bais, A., Zempila, M., Kazadzis, S., den Outer, P., Koskela, T., and Slaper, H.: Calculations of the human Vitamin D exposure from UV spectral measurements at three European stations, Photochem. Photobiol. Sci., 8, 45-51, 2009.

Knudsen, B., Larsen, N., Mikkelsen, I., Morcette, J.-J., Braahten, G., Kyrö, E., Fast, H., Gernand, H., Kanzawa, H., Nakane, H., Dorokhov, V., Yushkov, V., Hanse, G., Gil, M., and Shearman, R.: Ozone depletion in and below the Arctic vortex for 1997. Geophys. Res. Lett., 25, 627-630, 1998.

Koskela, T., Johnsen, B., Bais, A., Josefsson, W., and Slaper, H.: Spectral sky measurements, in Nordic intercomparison of ultraviolet and total ozone instruments at Izaña October 1996, Final report, edited by Kjeldstad, B., Johnsen, B., and Koskela, T., Finnish Meteorological Institute, Meteorological publications No. 36, Helsinki, 109-148, 1997.

Lakkala, K., Kyrö, E., and Turunen, T: Spectral UV Measurements at Sodankylä during 1990-2001, J. Geophys. Res., 108, 4621, doi:10.1029/2002JD003300, 2003.

Lakkala, K., Arola, A., Heikkilä, A., Kaurola, J., Koskela, T., Kyrö, E., Lindfors, A., Meinander, O., Tanskanen, A., Gröbner, J., and Hülsen, G.: Quality assurance of the Brewer spectral UV measurements in Finland, Atmos. Chem. Phys., 8, 3369-3383, doi:10.5194/acp-8-3369-2008, 2008.

Lakkala, K., Suokanerva, H., Karhu, J. M., Aarva, A., Poikonen, A., Karppinen, T., Ahponen, M., Hannula, H.-R., Kontu, A., and Kyrö, E.: Optical laboratory facilities at the Finnish Meteorological Institute - Arctic Research Centre, Geosci. Instrum. Method. Data Syst. Discuss., doi:10.5194/gi-2015-43, in review, 2016.

Lappalainen, N., Huttunen, S., Suokanerva, H., and Lakkala, K.: Seasonal acclimation of the moss Polytrichum juniperinum $H e d w$. to natural and enhanced ultraviolet radiation, Environ. Pollut., 158, 891-900, 2010. 
Manney, G., Santee, M., Rex, M., Livesey, N., Pitts, M., Veefkind, P., Nash, E., Wohltmann, I., Lehmann, R., Froidevaux, L., Poole, L., Schoeberl, M., Haffner, D., Davies, J., Dorokhov, V., Gernandt, H., Johnson, B., Kivi, R., Kyrö, E., Larsen, N., Levelt, P., Makshtas, A., McElroy, T., Nakajima, H., Parrondo, M., Tarasick, D., von der Gathen, P., Walker, K., and Zinoviev, N.: Unprecedented Arctic ozone loss in 2011, Nature, 478, 469-475, doi:10.1038/nature10556, 2011.

Mäkelä, J. S., Lakkala, K., Meinander, O., Kaurola, J. Koskela, T., Karhu, J. M., Karppinen, T., Kyrö, E., Leeuw, G., and Heikkilä, A.: In search of traceability: Two decades of calibrated Brewer UV measurements in Sodankylä and Jokioinen, Geosci. Instrum. Method. Data Syst. Discuss., doi:10.5194/gi-2015-40, in review, 2016.

Marenco, F., di Sarra, A., and De Luisi, J.: Methodology for determining aerosol optical depth from Brewer 300-320-nm ozone measurements, Appl. Opt., 41, 1805-1814, 2002.

Martz F., Turunen, M., Julkunen-Tiitto, R., Lakkala, K., and Sutinen, M.-L.: Effect of the temperature and the exclusion of UVB radiation on the phenolics and iridoids in Menyanthes trifoliata L. leaves in the subarctic, Environ. Pollut., 157, 3471-3478, doi:10.1016/j.envpol.2009.06.022, 2009.

Mayer, B. and Kylling, A.: Technical note: The libRadtran software package for radiative transfer calculations - description and examples of use, Atmos. Chem. Phys., 5, 1855-1877, doi:10.5194/acp-5-1855-2005, 2005.

McKinlay, A. F. and Diffey, B. L.: A reference action spectrum for ultraviolet induced erythema in human skin, CIE Research Note, CIE-Journal, 6, 17-22, 1987.

Meinander, O., Josefsson, W., Kaurola, J., Koskela, T., and Lakkala, K.: Spike detection and correction in Brewer spectroradiometer ultraviolet spectra, Opt. Eng., 42, 1812-1819, 2003.

Mitchell, B. G.: Action Spectra for ultraviolet photoinhibition of Antarctic phytoplankton and a model of spectral diffuse attenuation coefficients, in: Response of Marine Phytoplankton to Natural Variations in UV-B Flux, edited by: Mitchell, G., Sobolev, I., and Holm-Hansen, O., Proc. of Workshop, Scripps Institution of Oceanography, La Jolla, CA, 5 April 1990.
Savastiouk, V: A database implementation of data analysis and quality control for the Brewer, presentation at the 13th Brewer User Workshop, Beijing, China 12-16 September 2011, available at: https://www.wmo.int/pages/prog/arep/gaw/documents/ 13th_Brewer_d2_Savastiouk-Database.pdf (last access: 16 May 2016), 2011.

SCI-TEC Instruments Inc.: Brewer MKII Spectrophotometer, operator's manual, Saskatoon, Canada, 1999.

Setlow, R. B.: The wavelengths in sunlight effective in producing skin cancer: A theoretical analysis. P. Natl. Acad. Sci. USA, 71, 3363-3366, 1974.

Seckmeyer, G., Bais, A., Bernhard, G., Blumthaler, M., Booth, C., Disterhoft, P., Eriksen, P., McKenzie, R., Miyauchi, M., and Roy, C.: Instruments to Measure Solar Ultraviolet Radiation, Part 1: Spectral Instruments, World Meteorological Organization (WMO), Global Atmosphere Watch Report no. 125, 30 pp., 2001.

Slaper, H., Reinen, A. J., Blumthaler, M., Huber, M., and Kuik, F.: Comparing ground-level spectrally resolved solar UV measurements using various instruments: A technique resolving effects of wavelength shift and slit width, Geophys. Res. Lett., 22, 27212724, 1995.

Webb, A., Gardiner, B., Leszczynski, K., Mohnen, V. A., Johnston, P., Harrison, N., and Bigelow, D.: Quality Assurance in Monitoring Solar Ultraviolet Radiation: the State of the Art, World Meteorological Organization (WMO), Global Atmosphere Watch Report, 45 pp., 2003.

Webb, A. R., Gardiner, B. G., Martin, T. J., Leszczynski, K., Metzdoff, J., Mohnen, V. A., and Forgan, B.: Guidelines for site quality control of UV monitoring, Rep. Ser. 126, Environ. Pollut. Monit. Res. Programme, World Meteorol. Organ., Geneva, 1998.

WMO (World Meterorological Organization): Report of the WMOWHO Meeting of Experts on UVB Measurements, Data Quality and Standardisation of UV indicies, Global Atmopshere Watch Report No. 95, 1997. 